\title{
MODELO TRIPLE HELIX COMO ESTRATÉGIA DE GESTÃO DE CUSTOS EM INOVAÇÃO EM REDES DE MPE'S
}

\section{Dusan Schereiber -Universidade Feevale ${ }^{1}$}

Resumo: A inovação, como diferencial competitivo, começou a fazer parte do repertório das organizações, com maior ênfase, nas últimas décadas do século passado, apesar de ter sido apontada, já no início do século, como aspecto relevante para a gestão organizacional. No entanto, com cada vez maior número de organizações investindo em inovação e com a aceleração do ritmo do desenvolvimento científico e tecnológico, os custos de inovação cresceram, de tal forma, que se tornaram inacessíveis para as empresas de micro e pequeno porte. Ao mesmo tempo, percebe-se que as instituições de ensino, em todos os países, têm recebido investimentos de vulto para a organização de sua infraestrutura laboratorial e a capacitação de técnicos especializados. Desta forma, constatou-se a situação de alocação ineficiente de recursos para a pesquisa e desenvolvimento, com as instituições de ensino e pesquisa, dedicadas à pesquisa científica, descoladas da realidade empresarial e, de outro lado, as empresas, enfrentando custos crescentes para inovar e se manterem competitivas no mercado. Com o intuito de solucionar o impasse, foi concebido, no final dos anos sessenta, o modelo Triple Helix, por meio do qual é promovida a interação entre o meio acadêmico e empresarial, por intermédio governamental, gerindo os custos de inovação de forma mais eficiente. A importância deste modelo se percebe, com maior destaque, no caso de MPEs - empresas de micro e pequeno porte. O presente artigo relata 0 caso de uma rede de pequenas empresas, que reduziu os custos em $P \& D$, por meio do referido modelo.

Palavras-chave: Estratégia; Inovação; Rede de MPEs; Gestão de custos; Triple Helix.

\section{THE TRIPLE HELIX MODEL AS A COSTS MANAGEMENT STRATEGY IN INNOVATION NETWORKS IN SMALL BUSINESSES}

\begin{abstract}
Innovation as a competitive advantage has become part of the repertoire of organizations, with greater emphasis, in the last decades of the past century, although it was pointed out at the beginning of the century as relevant to organizational management aspect. However with increasing number of organizations investing in innovation and accelerating the pace of scientific and technological development, innovation costs grew so that became inaccessible to micro enterprises and small. At the same time it is noticed that the educational institutions in all countries, have received major investments for the organization of its laboratory and promoted the training of specialized technical infrastructure. Thus it was found the situation of inefficient allocation of resources for research and development, with educational and research institutions dedicated to scientific
\end{abstract}

${ }^{1}$ Email: dusan@feevale.br Endereço: Rua Bolívia 120 Pinheiros, CEP: 93042-160 - São Leopoldo, RS - Brasil

SCHEREIBER, D. Modelo Triple Helix como estratégia de gestão de custos em inovação em redes de MPE's. Revista de Empreendedorismo e Gestão de Pequenas Empresas, v.2, n.3, 2013. 
research, disconnected from business reality, and on the other hand, firms facing rising costs and to innovate remain competitive in the market. In order to resolve the deadlock, was designed in the late sixties, the Triple Helix model, through which is promoted interaction between the academic and business world, mediated by government, managing innovation costs more efficiently. The importance of this model can be seen most prominently in the case of MSEs - Micro enterprises and small. This article reports the case of small businesses have reduced costs in $R$ \& $D$ by means of this model network.

Key-words: Strategy; Innovation; Small Business; Cost Management; Triple Helix.

\section{Introdução}

A necessidade de concepção de diferenciais competitivos, com o objetivo de enfrentar a concorrência, foi sentida pelos dirigentes organizacionais, já no início do século passado. Visando contribuir para o debate e elucidar o tema de posicionamento estratégico das organizações, vários pesquisadores de destaque conduziram pesquisas e, com base nos seus resultados, apresentaram teses, que deram origem a vertentes teóricas, que serviram para fundamentar diversas abordagens que orientam os acadêmicos e executivos até os dias atuais (KAY, 1996; GHEMAWAT, 2002).

Dentre as teorias mais relevantes, destaca-se o modelo de análise SWOT, a "curva BCG" e o método de análise de portfólio e de unidades estratégicas de negócios (HAMEL; PRAHALAD, 1989). Além disso, verificou-se o início de um processo mais reflexivo, com foco em concepção de estratégias organizacionais no escopo mais amplo, desde a compreensão das diversas formas que as organizações podem assumir, na sua atuação no mercado, até as alternativas de arranjo de recursos organizacionais, visando o nível ótimo em termos de retorno econômico do investimento realizado pelos acionistas. Nesse sentido, as teorias organizacionais receberam contribuições de vertentes de áreas de conhecimento, como economia, psicologia, sociologia, antropologia, entre outras (KAPLAN; NORTON, 2004).

A confluência destas vertentes teóricas resultou em uma base mais robusta de concepção de estratégias organizacionais, convergindo, para um ponto em comum - a necessidade de diferenciação da organização, em termos de gestão, com ênfase em arranjo inovador de recursos disponíveis -. Em outras palavras, trata-se de inovação em redes de MPE's. Revista de Empreendedorismo e Gestão de 
constituir diferencial competitivo (GHEMAWAT, 2002). Aliás, a inovação, ou seja, o fazer diferente, seja em termos de produtos finais ou de forma alternativa (processo), empregando criativamente os recursos disponíveis e, consequentemente, obtendo diferentes resultados, já tinha sido abordada por Schumpeter (1982), que enfatizou a sua importância para as organizações.

Destarte, a inovação, como campo de estudo, encontrou seu espaço ao sol, passando a configurar, inclusive, como um requisito normativo institucional e legitimador das organizações (CHRISTENSEN, 2003). Com cada vez maior número das organizações se candidatando ao "lucro extraordinário do empreendedor inovador schumpeteriano", a atividade de pesquisa e desenvolvimento se tornou o foco central de destaque, no universo organizacional (CHAM, 2005). Como consequência direta, constatou-se, também, o aumento significativo de recursos aportados para a pesquisa científica e desenvolvimento tecnológico, além da crescente sofisticação de equipamentos e processos empregados em P\&D (DEB, 1996; KRAMER, 2002). O custo de inovar aumentou exponencialmente, impossibilitando o acesso à pesquisa da maioria das organizações, notadamente das de micro e pequeno porte (MILLER; MORRIS, 1998; MORRISON, 2002).

Ao mesmo tempo, as instituições de ensino, procurando acompanhar a evolução da ciência e da tecnologia, investem recursos relevantes para aprimorar sua infraestrutura laboratorial e, desta forma, preparar técnicos (corpo docente e discente) de alto nível de competência (DAGNINO, 2003). A referida preparação, entretanto, fica, muitas vezes, restrita ao campo teórico, encontrando reduzido respaldo empírico, frustrando, com frequência, as expectativas da sociedade e do meio empresarial (BRISOLLA et al., 1997).

Destarte, no final dos anos sessenta, do século passado, alguns autores conceberam o modelo Triple Helix, por meio do qual apresentaram as bases teóricas para a interação universidade-empresa, com mediação governamental (SABATO; BOTANA, 1975). O referido modelo procurou evidenciar as vantagens da interação da academia com as organizações, tanto em termos macro como micro, além de evidenciar formas pelas quais a aproximação poderia ocorrer (LEYDESDORFF; ETZKOWITZ, 1996). Dentre as vantagens, destaca-se a redução de custos de 
pesquisa e desenvolvimento de produtos e processos, para as empresas contratantes.

O modelo foi acolhido com entusiasmo, principalmente na esfera governamental, na maioria dos países, notadamente em agências dedicadas a prover o apoio às micro e pequenas empresas (MPEs). A razão do entusiasmo se fundamenta na alternativa de real redução de recursos, que estas agências vêm destinando para estimular a consolidação de redes de MPEs, como forma de aumentar a sobrevivência e "longevidade" destas organizações, as quais se encontram, na maioria das vezes, em condições precárias para enfrentar a concorrência de outros agentes de maior porte (TERRA; ETZKOWITZ, 2007).

O presente artigo foi elaborado com o objetivo de apresentar o caso de aplicação do modelo Triple Helix, por meio do qual a rede de MPEs teve acesso ao apoio em desenvolvimento tecnológico de uma universidade privada, de grande porte, na região sul do país, reduzindo, de forma relevante, os custos envolvidos na gestão da inovação de produtos e processos. A apresentação do caso evidencia os benefícios decorrentes desta alternativa de gestão de inovação, notadamente em empresas de pequeno porte. No texto, será realizada a análise da tipologia de custos que, desta forma, foi passível de compartilhamento, viabilizando, na percepção dos autores, análise reflexiva que poderá estimular a realização de novos estudos acerca do tema.

Inicialmente, será apresentada a revisão conceitual, referente à concepção estratégica e à gestão da estratégia, com foco em inovação, visando oferecer contribuições teóricas subjacentes ao posicionamento estratégico das organizações, facultando a análise dos dados empíricos. Como uma das alternativas de inovar, em especial para as micro e pequenas empresas, é o modelo Hélice Tripla, que consiste na aproximação da empresa com a academia, com a mediação do agente governamental, este será o tema desenvolvido na seção quatro

$\mathrm{Na}$ quinta e sexta seção da revisão teórica, serão apresentadas diversas vertentes, que tratam dos benefícios do modelo cooperativo e associativo para as micro e pequenas empresas, notadamente em relação ao compartilhamento de recursos, reduzindo custos e otimizando a utilização de bens de capital. $\mathrm{Na}$ sequência, será caracterizado o método de pesquisa empregado e tipificado o caso inovação em redes de MPE's. Revista de Empreendedorismo e Gestão de 
empírico. O artigo será finalizado com considerações acerca do caso em tela e sugestões quanto a futuras pesquisas.

\section{Estratégia}

As contribuições mais consistentes ao tema de estratégia, desde a sua concepção até a sua implementação, tiveram sua origem nos anos sessenta, do século passado, vinculadas, inicialmente, ao conceito de planejamento estratégico. Sloan e Chandler, apud Chandler (1992) definiram, como objetivo principal da estratégia, o retorno do capital. Todas as ações empreendidas pela corporação deveriam focar este objetivo. Na década seguinte, surgiram vários modelos de concepção de estratégias corporativas. Dentre elas, vale citar as pesquisas da Harvard Business School, com destaque para Andrews (1980), proponente do modelo de análise SWOT, baseado em observações empíricas, e os trabalhos das empresas de consultoria, como a Boston Consulting Group e McKinsey \& Company. Estas empresas se consagraram pela ferramenta de apoio à gestão denominada curva BCG e o método de análise de portfólio e de unidades estratégicas de negócios.

Analisando as definições de planejamento estratégico, Mintzberg (1973) argumentou que o planejamento não é sinônimo de definição de estratégias. 0 modo de estratégia deve adequar-se à situação, o que está mais ligado a uma perspectiva contingencial. $O$ autor sugere que, em relação a isso, os planos estratégicos deveriam especificar pontos finais (objetivos gerais) e rotas alternativas, mas deixando o gestor com a flexibilidade necessária para reagir a um ambiente dinâmico. Em 1978, o mesmo autor realizou uma pesquisa empírica longitudinal, da qual emergiram três pontos importantes: (i) a formação da estratégia pode variar entre ambientes dinâmicos e momentos burocráticos, com mediações da liderança entre esses momentos; (ii) a formação da estratégia se compõe de períodos distintos regulares; (iii) o estudo das relações entre estratégias intencionais e realizadas leva à compreensão do 'coração deste complexo processo organizacional'. Os estudos demonstraram dois tipos de estratégias: intencional e 
realizada, permitindo a combinação de três formas: a) estratégia deliberada = estratégia intencional que se realiza; b) estratégia não realizada = estratégia intencional que não se realiza, devido a má interpretação do ambiente ou mudanças durante a implementação; c) estratégia emergente = estratégia não intencionada, mas realizada.

Quase onze anos depois, Porter (1989) conseguiu reunir e sintetizar o conhecimento construído, até então, acerca do desenvolvimento de estratégias. Duas questões centrais embasam, segundo ele, a escolha da estratégia competitiva: (i) a atratividade das indústrias (ramos industriais), em termos de rentabilidade em longo prazo, e os fatores que determinam esta atratividade; (ii) os determinantes da posição competitiva, dentro de uma indústria. A estratégia competitiva deve surgir de uma compreensão sofisticada das regras da concorrência, que englobam as cinco forças competitivas: (1) Entrada de novos concorrentes; (2) Ameaça de substitutos; (3) Poder de negociação dos compradores; (4) Poder de negociação dos fornecedores; e (5) Rivalidade entre os concorrentes existentes. Para o autor, os dois tipos básicos de vantagem competitiva, combinados com o escopo de atividades da organização, levam a três estratégias genéricas, para alcançar o desempenho acima da média em uma indústria: (i) Liderança de Custo; (ii) Diferenciação; e (iii) Enfoque (no custo ou na diferenciação).

Outros pesquisadores, do campo de estratégia, perceberam a relação de dependência com uma das derivações da teoria mainstream de economia - a RBV (Resource Based View). Abordada, inicialmente, no campo econômico, por Penrose (1959), o assunto foi retomado, de forma mais consistente, por pesquisadores em administração, apenas na década de oitenta (WERNERFELT, 1984) e noventa (MAHONEY; PANDIAN, 1992). A propriedade de recursos escassos valiosos, monopólio advindo de proteções e barreiras para competidores e a partir de empreendimentos schumpeterianos, associados ao empreendedorismo e riscos (que se perdem com a difusão do conhecimento) e de recursos específicos à firma, pode representar a vantagem competitiva.

A abordagem sistêmica, pesquisada por Whittington (2002), explica as diferenças entre as empresas, com base em sistemas sociais e econômicos em que estão inseridas. Identifica, também, a influência de estruturas internas, na definição inovação em redes de MPE's. Revista de Empreendedorismo e Gestão de Pequenas Empresas, v.2, n.3, 2013. 
de estratégias e políticas, incluindo as micropolíticas de indivíduos e departamentos, os grupos sociais, interesses e recursos do contexto circundante. As variáveis da perspectiva sistêmica incluem classe e profissões, nações e estados, famílias e gêneros. São importantes, portanto, para a teoria sistêmica, as diferenças entre os sistemas sociais de países e as mudanças dentro dos sistemas sociais destes. .

A abordagem sistêmica, com foco intraorganizacional, de Kaplan e Norton (2004), evidencia que nenhuma área da organização trabalha sozinha, uma vez que cada ação, feita por uma área, impacta em cada uma das outras, sendo essa ação refletida nos resultados financeiros da organização. Prevalece a visão do processo estratégico, como um processo de formulação e implementação, sendo a formulação feita em conjunto, para obter o comprometimento da organização. Os autores destacam a importância dos ativos intangíveis e as suas relações e consequências para a execução da estratégia corporativa.

\section{Estratégia com foco em inovação}

Do ponto de vista da gestão e com os olhos voltados para o mercado, a inovação é definida por Westwood e Sekine (1988) como o processo pelo qual, às vezes, as invenções são transformadas em produtos ou sistemas economicamente sustentáveis. A sustentabilidade econômica do produto novo também está vinculada, diretamente, ao conceito de utilidade, destacado por Stokes (2005), ao apresentar o Quadrante de Pasteur, fundamentado em pesquisa básica inspirada na sua utilização, ressaltando quatro questões conceituais relacionadas à pesquisa: (i) caracterização da pesquisa; (ii) os objetivos que devem ser levados em conta; (iii) possibilidade de redução das duas dimensões a uma; e (iv) tempo até a aplicação.

Tidd, Bessant e Pavitt (1997) e Reinl e Kelliher (2010) entendem que o desenvolvimento de novos produtos representa uma competência importante, em virtude do ambiente externo permanentemente em mudança, que, desta forma, oferece oportunidades para criar o novo, surpreender o mercado e assumir novas posições. Como exemplo, pode ser destacado o conjunto de alterações na legislação ambiental, em vários países, tanto nos mais desenvolvidos, como nos 
países emergentes, que cria novos marcos regulatórios concernentes a limites de emissão de poluentes. Ao mesmo tempo em que este fato pode representar uma ameaça a muitas organizações, por outro lado, aquela empresa, que possui esta competência, pode aumentar a sua participação no mercado.

Também Berman e Hagan (2006) apresentaram um modelo de estratégia de negócios, baseada em tecnologia. O conceito e os princípios de um processo de estratégia de negócios, combinado com a visão de mercado e know-how tecnológico, permite às empresas transpor diferentes setores e atingir taxas superiores de inovação. Esta abordagem exige o reconhecimento, por parte da empresa, de que a inovação se tornou um fator crítico para o crescimento sustentável e surge da interseção da visão de mercado e do know-how tecnológico.

Explorando a relação entre estratégia e inovação tecnológica, Curry e Clayton (1992) definem três categorias de estratégias tecnológicas: (i) adotar e adaptar; (ii) inovar de forma incremental; (iii) inovar de forma disruptiva. Cada uma destas categorias corresponde a, significativamente, diferentes posturas de negócios e de comportamentos de gestão. Existem circunstâncias onde cada uma representa a melhor estratégia a ser adotada e cada uma apresenta diferentes gradações de risco e de custos.

Entende-se que a gestão da inovação se refere ao contexto estratégico e organizacional dos processos individuais de inovação, com o objetivo de produzir produtos bem sucedidos no mercado, e processos inovadores, com o objetivo de racionalização de tempo e de recursos. Para Christensen (2002), a gestão da inovação inclui, obrigatoriamente, os elementos como marketing e produção e entende que a organização, que pretende obter êxito na implementação de processo de inovação, deve procurar integrar as atividades alinhadas e contemplar esta prioridade na sua estratégia organizacional.

Henard e McFadyen (2006) abordam a inovação, realizada por meio de processos de P\&D, destacando a importância das duas dimensões de conhecimento acumulado e de capacidade absortiva - em profundidade e amplitude - para as atividades de $\mathrm{P} \& \mathrm{D}$, que é a área organizacional que apresenta a competência técnica e conceitual para a condução das atividades de inovação dos produtos. A profundidade do conhecimento acumulado reflete o investimento prévio para adquirir inovação em redes de MPE's. Revista de Empreendedorismo e Gestão de 
o conhecimento relevante e a amplitude se refere à utilização que se dá ao conhecimento acumulado.

O processo de experimentação faz parte da rotina de P\&D industrial, onde a inovação pode ser definida como a transformação do conhecimento da empresa, incorporado na sua linha de produtos, que satisfazem necessidades de seus clientes atuais ou criam novas necessidades (MORT, 2001). As empresas são sistemas de inovação e inovações são baseadas na divisão de trabalho em geração e utilização de conhecimento. Esta especialização molda a estrutura interna organizacional, os meios de comunicação e as rotinas operacionais (LOASBY, 2001). O principal papel da gestão de P\&D, para Grant (1996), é estabelecer a coordenação necessária para a integração do conhecimento, implicando, diretamente, na configuração do posicionamento estratégico organizacional.

\section{Interação universidade-empresa}

Com base na sua pesquisa sobre os resultados da interação U-E (Universidade-Empresa), na Unicamp, Brisolla et al. (1997) afirma que, apesar da convicção generalizada de que as universidades devem e podem desempenhar um papel muito importante no encurtamento do gap tecnológico, que constitui sério obstáculo para o crescimento econômico do País, ainda não há consenso sobre a melhor forma de interação. A autora entende que as tentativas do governo de incentivar o estreitamento de laços, entre universidade e empresa, obtiveram resultados aquém do esperado. No entanto, percebe-se que o ambiente de competição intensa, no mercado, vem obrigando as empresas a buscar parcerias com instituições de ensino e pesquisa. Além disso, identificam-se novas configurações para os sistemas de inovação - redes de inter-relação entre empresas, universidades e institutos de pesquisa. Nessas redes, que constituem a base da nova sociedade do conhecimento, a autora entende que a universidade terá, necessariamente, um papel relevante.

Em estudo realizado sobre o desenvolvimento da América Latina, Sabato e Botana (1975) destacaram que a inovação encontra diversos obstáculos e enfrentá- 
los exige do governo investimentos na estrutura produtiva e infraestrutura científicotecnológica. A atuação do governo tem, como objetivo, formular e implementar políticas no âmbito científico-tecnológico de forma deliberada; a infraestrutura científico-tecnológica é responsável pela capacidade criadora, desenvolvendo a ciência e a tecnologia, e a estrutura produtiva tem como função revolucionar o sistema de produção, através de inovações. O relacionamento entre estrutura produtiva e instituições de ensino e pesquisa é o mais difícil.

Outros autores conceberam modelos semelhantes. O principal deles é a "Hélice Tripla", de Leydesdorff e Etzkowitz (1996). O modelo toma as formas tradicionais de diferenciação institucional entre as universidades, empresas e governo, como o ponto de partida. A perspectiva evolucionária agrega, a esta configuração histórica, a noção de que as pessoas modelam, de forma reflexiva, estas instituições. O referido modelo leva em conta o crescente papel do setor de conhecimento em relação à infraestrutura econômica e política da sociedade. A diferença entre naçãoestado e economia leva à análise de diferenciação funcional entre a ciência e mercado e de diferenciação institucional entre o controle privado e público. Percebese, desta forma, três dinâmicas claras e distintas: (a) a dinâmica econômica do mercado; (b) a dinâmica interna da produção do conhecimento; e (c) a governança da interface, em diferentes níveis.

Terra e Etzkowitz (2007) destacam a importância da capacidade de adaptação dos três atores, que compõem a Hélice Tripla, às contingências ambientais, em permanente transformação. Neste contexto, a empresa, de base tecnológica, deverá estar ancorada na fabricação de produtos inovadores, além de interagir com as universidades e centros de pesquisa. A universidade, por sua vez, deverá possuir o perfil de universidade empreendedora, com a tarefa de promover 0 desenvolvimento econômico e social, através de novas estruturas organizacionais e com a missão de garantir a inserção, no mercado globalizado, de todo o seu corpo docente e discente. E, finalmente, o governo, denominado por Terra e Etzkowitz (2007) como "governo da nova era", deverá ser participativo, viabilizando uma interação efetiva com os demais atores, dialogando e construindo, com base no consenso, o plano político que possibilite a efetiva parceria. 


\section{As redes de cooperação de MPEs}

As MPEs eram responsáveis, no ano de 2005, pela geração de 57,2\% dos empregos e 26,0\% dos salários. Esta participação tem crescido, a cada ano, implicando em crescente representatividade, tanto econômica como política, pois o custo de se criar um emprego, em uma pequena empresa, é inferior ao custo de geração de um posto de trabalho, em uma empresa de maior porte (IBGE, 2014). A importância do segmento das MPEs motivou a criação, no início dos anos noventa, do século passado, de uma agência governamental para apoiar este segmento.

A atuação da agência de apoio restringe-se às MPEs. Existem, no país, dois critérios predominantes para a classificação de empresas por porte: o valor do faturamento anual e o número de empregados (MULS, 2008). O critério de faturamento anual serve de referência para programas do governo federal, para a concessão de incentivos fiscais, parafiscais e de fomento, como acesso à tecnologia. O faturamento anual é, também, o critério que consta do Estatuto da Micro e Pequena Empresa. O critério de número de funcionários, por sua vez, é utilizado para fins estatísticos, pelo próprio governo federal, por meio do IBGE e demais autarquias vinculadas ao governo. Este último critério é utilizado, também, pela agência (DUTRA, 2009).

Desde 2001, a política de atuação da agência, em todo o país, está voltada à abordagem por APLs. Esta política foi definida a partir de pesquisas e estudos realizados por professores e pesquisadores, das principais universidades brasileiras, voltados a políticas para o desenvolvimento local e setorial dos agrupamentos de empreendimentos, de micro e pequeno porte. Estudos e pesquisas de doutorado e mestrado cristalizaram conceitos, que foram testados, na prática, em alguns agrupamentos territoriais de MPEs, em vários estados brasileiros. Os resultados obtidos, a partir de aplicações-piloto, justificaram a abordagem a partir da coletividade das MPEs, de acordo com o conceito vigente de Arranjos Produtivos Locais (ZACCARELLI et al., 2008). 
Lastres e Cassiolato (2001) definem os arranjos produtivos locais como redes de agentes localizados no mesmo território, sendo que estes agentes não são apenas empresas (produtores, fornecedores, prestadores de serviços, entre outros) e suas diversas formas de associação, mas, também, diversas outras instituições públicas e privadas (orientadas à prestação de serviço de capacitação de recursos humanos, pesquisa, desenvolvimento, engenharia, consultoria e financiamento, entre outros). Com base nos resultados de suas pesquisas, os autores afirmam que, para intensificar as atividades inovativas em APLs, há necessidade de implementar políticas públicas, construídas com base em recursos, organizações, instituições locais e suas relações (CASAROTTO; PIRES, 1999; GIULIANE, 2007).

Segundo Lastres e Cassiolato (2005) e Dutra (2009), os arranjos e sistemas produtivos locais são construídos com base no seu histórico, que evidencia a sua identidade idiossincrática em termos sociais, culturais, políticos e econômicos. No entanto, os sistemas apresentam maior interação, cooperação e confiança entre os atores, do que nos arranjos produtivos locais. É neste ponto que os autores percebem a importância da ação de políticas, tanto públicas como privadas, que possam resultar em criação de um ambiente favorável à interação, a longo prazo. A abordagem de ASPIL - Arranjos e Sistemas Produtivos e Inovativos Locais caracteriza-se, particularmente, por ressaltar a importância do aprendizado e da capacitação, envolvendo empresas e diferentes conjuntos de atores, como elementos centrais de dinamização do processo inovativo.

Realizando a pesquisa com empresas de pequeno porte, associadas em rede, Donckels e Lambrecht (1997) e Giuliane (2007) verificaram que três fatores porte de empresa, nível de instrução do empresário e estratégia de crescimento influenciam a forma e a intensidade de troca de informações, dentro da rede. A pesquisa demonstra a importância de redes de contato com outras empresas e a correlação, dos três fatores, com o maior ou menor grau de sucesso, na consolidação da rede de pequenas empresas.

Uma das formas de associação de empresas de micro e pequeno porte, contemplada com incentivos do governo federal, é a de consórcio de exportação. Para Minervini (2001), o tipo mais comum dos consórcios de exportação é o operacional. Os consórcios operacionais objetivam facilitar o processo de inovação em redes de MPE's. Revista de Empreendedorismo e Gestão de 
exportação, atuando tanto sobre os aspectos jurídicos como operacionais, para atender os requisitos específicos do mercado externo. Nesta atuação, destaca-se a concepção e adoção por todas as empresas envolvidas, de uma marca em comum, especialização, capacitação e padronização de processos produtivos, identificação e homologação de fornecedores para o grupo e desenvolvimento de um plano de marketing e de investimentos em bens de capital.

\section{As vantagens de redução de custos decorrentes da externalização de P\&D}

A inovação organizacional, independente da ênfase ou priorização, seja em concepção e desenvolvimento de novos produtos, revisão e alteração de processos, de marketing ou de forma de organizar os recursos, bem como de reposicionamento estratégico, está condicionada à existência do conhecimento específico e atualizado, notadamente, de natureza técnica, da área do conhecimento subjacente ao setor econômico, no qual a organização está inserida. Este conhecimento, que subsidia e respalda as atividades de inovação, pode ser gerado internamente ou adquirido externamente, sendo, na maioria das vezes, organizado e tratado pela área de pesquisa e desenvolvimento (P\&D).

A área de P\&D representa, dentro da organização, a fonte de geração de conhecimentos especializados, que podem agregar valor ao portfolio de produtos que a empresa oferta no mercado e estuda métodos mais eficientes de produção, com menor custo e menor tempo de execução (BOGLIACINO; CARDONA, 2010). Muitos autores de teorias organizacionais, de abordagem econômica, percebem a lógica de custos de transação como argumento central no processo decisório, no tocante à questão "Fazer ou Comprar" (COASE, 1937; WILLIAMSON, 1996; SWEDBERG, 2003), segundo a qual, comprar os serviços de P\&D apresenta menor custo.

Segundo Swedberg (2003), a firma deverá optar por fazer P\&D, internamente, apenas em caso de transações frequentes, incertas e quando estas vierem a demandar investimentos especiais, ou seja, aplicação de recursos em ativos específicos. Do contrário, deverá ser usado o mercado. Coase (1937) argumenta 
que a firma tenderá a ser maior quando os custos de transações internas forem menores do que os realizados no mercado, ou seja, quando o custo de realização de P\&D, dentro da organização, for inferior à sua contratação no mercado, o que, de certa forma, contradiz evidências constatadas por outros autores. Dentre eles, destacam-se Alchian e Demsetz (2005), que constataram acréscimos de custos internos decorrentes da necessidade de supervisão e controle de processos internos.

No entanto, para diversos autores, com destaque para Langlois (2003), é possível afirmar que a especialização se tornou a palavra chave nos anos noventa, juntamente com a crescente flexibilização e terceirização. Apesar de todas as dificuldades para terceirizar as atividades, muitas organizações chegaram à conclusão que, à luz da teoria de custos de transação, os benefícios superam as desvantagens. Morrison (2002) destaca que a externalização de P\&D permite aumentar a produtividade de P\&D, evita o inchaço dos quadros internos de pesquisadores e o comprometimento de recursos financeiros em ativos específicos, destinados à pesquisa. Kramer (1998) acrescenta que a externalização de P\&D oferece, como principais vantagens, lucratividade, flexibilidade, maior rapidez e inovação.

Hertog, Thurik e Roy (1993), Deb (1996) e Goel (1999) argumentam que a externalização de P\&D proporciona, para as empresas, vantagens como a identificação de oportunidades de desenvolvimento de novos produtos, a redução de riscos e de valores investidos. Deduzem que a organização que externaliza, ao menos parte de P\&D, poderá obter maior lucratividade, advinda do menor tempo de desenvolvimento de produtos inovadores e da possibilidade de gestão simultânea de vários projetos.

Boath, Hess e Munch (1996) destacam, como principal vantagem da externalização de P\&D, o uso apropriado de recursos flexíveis e mais eficientes, proporcionando a redução de custos. Defendem que a empresa deve focar os esforços de P\&D interno em pesquisas de produtos estratégicos e centrais, externalizando os demais desenvolvimentos, no que são apoiados por Harris et al (1996), que recomendam que a decisão de externalizar P\&D deve ser baseada nas seguintes variáveis: a centralidade e importância da pesquisa para a organização, o inovação em redes de MPE's. Revista de Empreendedorismo e Gestão de 
papel estratégico da competência que provêm da pesquisa e o valor agregado da tecnologia resultante da pesquisa.

Subjacente às vertentes teóricas, que abordam o tema de externalização de atividade sob o ponto de vista de estratégia organizacional, existe, na literatura, a abordagem que procura tecer suas considerações à luz da gestão estratégica de custos. Esta abordagem encontra respaldo, principalmente, na teoria dos custos de transação, visão baseada em recursos e a teoria de finanças, com destaque para as proposições de Nakagawa (1993), Megliorini (2006) e Ferreira (2007) sobre a estrutura de capital, com foco sobre o custo do capital e a teoria dos investimentos.

A essência, da referida abordagem, é representada pela necessidade de planejamento prévio dos investimentos em bens de capital, sua tipificação e caracterização, em termos de utilização efetiva (em horas máquina) e sua alocação em projetos de pesquisa, os quais devem apresentar as estimativas de retorno econômico esperado (BORNIA, 2002). O planejamento também deverá contemplar a previsão de horas homem a serem utilizadas, segmentadas e categorizadas por tipo de profissional a ser alocado, em cada um dos projetos, avaliação de horas a serem consumidas no processo de pesquisa ou, até, de manutenção. Da mesma forma, deverá ser previsto o consumo de materiais auxiliares ou secundários, no referido processo de pesquisa (LEONE, 2000; MARTINS, 2006).

No tocante ao investimento em bens de capital, não pode ser omitida a taxa de depreciação, decorrente do desenvolvimento tecnológico, o qual, forçosamente, obrigará a organização a substituir o equipamento antes do prazo da vida útil do mesmo, em virtude da necessidade de se manter em condições de competir com os demais concorrentes e de preservar os níveis de produtividade. Trata-se de perseguir o objetivo de otimização na utilização de recursos, ou seja, atingir o nível ótimo de retorno sobre os ativos da firma (VANDERBECK; NAGY, 2003; MARTINS, 2006).

Desta forma, será facultado aquilatar o montante de custos, vinculado à decisão de internalizar as atividades de pesquisa e desenvolvimento, de forma global, por projeto e até por produto. Agregando as variáveis de cunho mais subjetivo, seja de gestão do conhecimento ou de vetor estratégico, o gestor da área de P\&D poderá iniciar o processo reflexivo e negocial com instituições de pesquisa, 
de ensino ou com consultores individuais, na área tecnológica em tela, para averiguar a possibilidade, as vantagens e desvantagens da externalização.

À luz de teorias de gestão estratégica de custos, destaca-se, como a mais relevante vantagem da externalização, a liquidez decorrente da redução do montante de recursos alocados e, por conseguinte, imobilizados, em bens de capital, ou seja, em máquinas e equipamentos necessários para a condução do processo de P\&D. Esta decisão resultará, inevitavelmente, na melhoria dos indicadores de retorno sobre o total do ativo, o que poderá atrair investidores, dispostos a adquirir ações da companhia (COGAN, 2000; SILVESTRE, 2002). Além disso, com o recurso em caixa, a empresa poderá usufruir de oportunidades de investimento que podem surgir ao longo do período de pesquisa de novos produtos, que chega, normalmente, até cinco anos ou mais. Não se pode deixar de mencionar a redução significativa de riscos, aos quais uma empresa descapitalizada está sujeita, principalmente em contexto econômico instável e imprevisível.

A seguir, será apresentado o caso empírico de rede de MPEs, que foram beneficiadas pelo modelo Triple Helix, mediado pela agência do governo federal, com o objetivo de apoiar o empreendedorismo e as micro e pequenas empresas no Brasil, obtendo o acesso ao desenvolvimento tecnológico, junto a uma universidade particular de grande porte, no sul do país.

\section{Método de pesquisa}

O método de pesquisa escolhido foi o estudo de caso, por se entender que apresenta melhor aderência ao objetivo e às questões que nortearam o estudo. Tull e Hawkins (1976, p. 323) afirmam que "um estudo de caso refere-se a uma análise intensiva de uma situação particular". De acordo com Yin (1989), a preferência pelo uso do estudo de caso deve ocorrer na pesquisa de eventos contemporâneos, em situações onde os comportamentos relevantes não podem ser manipulados, mas onde é possível se fazer observações diretas e entrevistas sistemáticas. O estudo foi realizado com uma visão externa dos pesquisadores, sem envolvimento ou manipulação de quaisquer informações, levantando fatos contemporâneos. Dentre 
as aplicações para o estudo de caso, citado por Yin (1989), nesse trabalho procurouse descrever o contexto da vida real e realizar uma avaliação descritiva.

O estudo de caso é útil, segundo Bonoma (1985, p. 206 e 207), "... quando um fenômeno é amplo e complexo, onde o corpo de conhecimentos existente é insuficiente para permitir a proposição de questões causais e quando um fenômeno não pode ser estudado fora do contexto no qual ele naturalmente ocorre". Os objetivos do Método do Estudo de Caso não são a quantificação ou a enumeração, "... mas, ao invés disto: (1) descrição; (2) classificação (desenvolvimento de tipologia); (3) desenvolvimento teórico; e (4) o teste limitado da teoria. Em uma palavra, o objetivo é compreensão" . Na parte empírica deste estudo, descrevem-se as situações que ocorreram, confrontando-as com a teoria, de forma restrita às organizações pesquisadas.

Trata-se da realização de um estudo de caso múltiplo, comparativo de desempenho anual, em dois consórcios de exportação, constituídos de organizações industriais da cadeia coureiro-calçadista, da região Metropolitana de Porto Alegre, que produzem para o mercado local e para exportação. A pesquisa foi realizada por meio de entrevista em profundidade, com os responsáveis por sete empresas que fazem parte de duas redes constituídas. Para evidenciar os elementos e categorias, com o objetivo de contrastá-los com a literatura revisada, foi utilizada a análise de conteúdo, seguindo o modelo proposto por Demo (2006).

\section{Caracterização dos casos e análise dos resultados}

A indústria de calçados exibe baixo nível de barreira à entrada de novos concorrentes, utiliza tecnologia de fácil acesso, é intensiva na utilização de mão de obra e as economias de escala são pouco expressivas, de acordo com Costa (2002). A produção pode ser realizada em uma única empresa ou em várias , o que facilita a formação de aglomerados industriais, concentrando, em um mesmo local geográfico, fornecedores e fabricantes do produto final (GORINI;SIQUEIRA, 2000).

O complexo calçadista do Vale do Sinos pode ser classificado como um cluster, pois apresenta várias condições que sustentam este modelo. $\mathrm{Na}$ área do 
Vale do Sinos, em um raio geográfico de $30 \mathrm{~km}$, existe a instalação desde produtores de matérias-primas básicas até produtores de máquinas e equipamentos para o setor calçadista. Além de estar estabelecida uma cadeia vertical de produção de calçados, há uma relação horizontal entre as empresas, sob forma de subcontratação para a elaboração de partes da produção. Nesta relação, estão inseridas empresas de todos os portes, mas predominam organizações de micro e pequeno porte (85\%, em 2004).

Alguns produtos, principalmente aqueles classificados como componentes e acessórios, podem ser segmentados em duas categorias. A primeira possui características semelhantes à de commodities, tais como as couraças, contrafortes, adesivos e produtos químicos, entre outros. Já a segunda categoria é muito influenciada pelas tendências de moda, onde predominam fatores como a criatividade e a inovação. Estes últimos produtos têm um tempo de vida mais curto, exigindo constante atualização e novos lançamentos (ASSINTECAL, 2006). Trata-se de desenvolvimento tecnológico, melhoria dos padrões de qualidade da indústria e capacitação para a exportação.

As MPEs encontravam-se, normalmente, à margem do referido processo de busca e aquisição de novas tecnologias, ficando na dependência de produção sob encomenda, de compradores que forneciam a tecnologia requerida, tomando, como contrapartida, maior parte da margem de contribuição, confirmando o teor dos resultados de pesquisas de Casarotto e Pires (1999), Dagnino (2003) e Terra e Etzkowitz (2007). Desta forma, perpetuavam a situação de dependência do fabricante de pequeno porte, o que favorecia, sobremaneira, o comprador que impunha suas condições, representadas, não apenas, pelo preço final, como também por todas as demais cláusulas negociais como prazo médio de fabricação e entrega do pedido. Os compradores do exterior chegavam a instalar, na região, seus agentes de compra, buying agents, remunerados com a redução da margem de contribuição deduzida do fabricante (GORINI; SIQUEIRA, 2000; COSTA, 2002).

A situação começou a mudar nos anos noventa, pela ação da agência nacional de apoio a MPEs, quando seu grupo de consultores articulou, com base no diagnóstico da situação, a proposta de capacitação da rede das indústrias calçadistas da região (ASSINTECAL, 2006). Na aprovação do projeto, indicava-se inovação em redes de MPE's. Revista de Empreendedorismo e Gestão de 
que as empresas deveriam atuar de forma articulada, buscando aumentar o padrão médio da qualidade dos produtos, modernizar os padrões de produção e de gerência e adotar práticas comerciais inovadoras, como forma de obter ganhos de escala, para participar do mercado externo, ampliar as exportações do setor de componentes e contribuir para a ampliação das vendas externas do setor calçadista. Assim, foi estabelecido um compromisso formal das entidades, com objetivo de alcançar as metas. Este tipo de medida, para aumentar o nível de competitividade, foi detectado em estudos anteriores, de autores como Brisolla, Corder, Gomes e Mello (1997), Donckels e Lambrecht (1997) e Dagnino (2003).

O processo de capacitação tecnológica incluiu, no desenho, a participação de uma universidade local, de grande porte, que foi contratada para prover o grupo de empresas com soluções em termos de design de produtos e reestruturação de processos internos, fundamentais para estimular as atividades de inovação (BERMAN;HAGAN, 2006; CHRISTENSEN;RAYNOR, 2003). Este atendimento foi viabilizado, técnica e financeiramente, devido à articulação e apoio da agência mediadora, com recursos disponibilizados pelo governo federal, dentro do programa concebido, conceitualmente, à luz do modelo de Hélice Tripla.

Através do trabalho de articulação de profissionais, contratados com esta finalidade específica, as empresas setorialmente classificadas foram contatadas e convidadas a participar do programa. Os próprios articuladores organizavam os encontros e mediavam as discussões, dentro do modelo de gestão recomendado por autores como Casarotto e Pires (1999) e Lastres e Cassiolato (2007). Desta forma, as empresas atendidas no projeto passaram a operar com marca própria, diversificaram os mercados consumidores, ampliaram o leque de produtos, bem como realizaram investimentos na inovação de produtos e processos.

Ao analisar os resultados de 7 empresas do grupo, foi possível constatar que, após 12 meses (ano 2009), os indicadores de natureza financeira e contábil confirmam a apropriação dos ganhos. Na comparação com o mesmo período do ano anterior ao programa, as empresas apresentaram crescimento de lucro operacional entre $27,1 \%$ a $114,6 \%$. O retorno sobre o Ativo Total, que demonstra o nível de competência na gestão de recursos, cresceu entre $111,5 \%$ a $279,4 \%$. Os índices de liquidez corrente tiveram crescimento entre $62,6 \%$ e $173,4 \%$, o custo médio de inovação em redes de MPE's. Revista de Empreendedorismo e Gestão de Pequenas Empresas, v.2, n.3, 2013. 
desenvolvimento, por produto, foi reduzido, em percentuais que variaram de $44 \%$ a $69 \%$ e o tempo médio de desenvolvimento por produto reduziu, em média, de 6 a 22 dias (BORNIA, 2002; MARTINS, 2006; FERREIRA, 2007). Além disso, com a atuação conjunta, sob a orientação de extensionistas universitários, as empresas conseguiram negociar alongamento dos prazos de suas compras, sem majoração de valores, aumentando os prazos médios de pagamento de 35,4 dias para 49,7 dias.

No entanto, também foi possível constatar que as organizações de menor porte, que não tinham realizado aportes relevantes, para a organização interna e de inovação de produtos e processos, foram beneficiadas com um ganho proporcionalmente superior ao das empresas de porte maior e com histórico de investimento em inovação. Esta constatação baseia-se nos indicadores financeiros e contábeis evidenciados, onde as empresas de maior porte apresentaram os menores percentuais de crescimento, menor variação em número de dias de redução do período de desenvolvimento de produtos e de aumento de prazo para pagamento de compras, por já estarem usufruindo destes benefícios antes do programa. Entende-se, também, que as estruturas menos hierarquizadas e mais flexíveis, de organizações menores, podem ter contribuído para um maior ganho, com a introdução da cultura de inovação (CURRY;CLAYTON, 1992; MILLER;MORRIS, 1998; BERMAN; HAGAN, 2006).

No tocante à verificada otimização de recursos, foco do modelo Triple Helix, é possível afirmar que a mesma foi decorrente não apenas da inovação de produtos (DEB, 1996; GOEL, 1999; HENARD \& MCFADYEN, 2006), mas, também, de processos de gestão, que resultaram em menor nível de imobilização do capital de giro, em virtude de compartilhamento de infraestrutura, disponibilizada pela universidade local, facultando a aplicação dos recursos para o financiamento da atividade operacional, como aquisição de insumos, comercialização de produtos, contratação de pessoas, como, também, de todos os demais processos de suporte.

$\mathrm{Na}$ percepção dos dirigentes, das sete empresas entrevistadas, o projeto facultou o reposicionamento estratégico, por permitir o acesso à tecnologia atual, a custo reduzido. 


\section{Considerações finais}

A importância de constituição de um diferencial competitivo para as organizações foi evidenciada, no início do século passado, por vários pesquisadores do campo de estratégia empresarial. Com o crescente acirramento da competição pelos mercados e a entrada de novos concorrentes, a diferenciação por meio de escala e escopo deixou de ser suficiente para assegurar a continuidade de várias operações. Foi a partir desta constatação, que as organizações perceberam o potencial diferenciador na inovação, cujas bases conceituais tinham sido lançadas por Schumpeter (1982).

A introdução de práticas inovadoras, dentro do ambiente organizacional, estimulou a interpretação das situações e eventos de rotina, à luz de novas abordagens, na pesquisa e no desenvolvimento de soluções e na concepção de novos métodos de produção, incluindo rearranjo de recursos disponíveis à organização. A maioria das empresas aderiu ao novo modelo, notadamente, nas últimas décadas do século passado, com o advento e consolidação da atuação global das organizações e a ação dirigida a múltiplos mercados.

Como consequência desta nova orientação estratégica, das organizações, para a ação inovadora, associada à aceleração do ritmo da evolução científica e tecnológica mundial, os custos relativos ao processo de pesquisa e desenvolvimento tiveram um crescimento acima do esperado. Além disso, nem todos os produtos inovadores obtiveram a confirmação de sua viabilidade econômica, pela demanda do mercado, gerando, muitas vezes, prejuízos às organizações e obrigando seus dirigentes organizacionais à implantação de controles em P\&D, além de buscar outras alternativas para a redução de custos para inovar.

Destarte o modelo Triple Helix, de interação entre universidade, empresas e governo, com o objetivo de otimizar os investimentos em inovação, em termos macro, veio ao encontro dos interesses destes três atores. No caso das empresas, o modelo que embasa, conceitualmente, a aproximação do meio produtivo com o ambiente acadêmico, com vistas à cooperação para a inovação, representa uma alternativa para reduzir valores alocados em investimentos em ativo imobilizado, com previsão de retorno a longo prazo, além da flexibilidade do vínculo com a 
mãodeobra altamente especializada. Já para a universidade, o modelo oportuniza a vinculação da teoria com a prática, além da legitimação junto ao setor empresarial. Neste contexto, o governo cumpre o seu papel de estimulador do desenvolvimento científico e tecnológico, com a real chance de reduzir valores a serem alocados, do erário público, para este fim.

O referido modelo se tornou especialmente importante para as MPEs - micro e pequenas empresas que, devido às suas características estruturais e fragilidades naturais, decorrentes de reduzida disponibilidade de capital, baixo nível de tecnologia embarcada, mão de obra com baixo grau de conhecimento e competência, entre outras, estavam, na sua maioria, excluídas do processo de inovação. No entanto, devido à representatividade do segmento de MPEs na economia nacional, com dimensões relevantes, tanto na geração de emprego e renda, como em termos políticos, a ponto de motivar a constituição de uma agência governamental com o foco específico de fornecer apoio às MPEs, esta situação mudou com a aplicação do modelo de redes e Triple Helix.

Em todo território nacional, a agência do governo estimulou a constituição de redes de cooperação, com o intuito de facultar o acesso aos programas capacitadores da agência e acesso à inovação, por meio de interação com as instituições de ensino próximas. Esta ação ocorreu, também, na região do Vale dos Sinos, onde as empresas do cluster coureiro calçadista obtiveram assessoria para aprimoramento de seus produtos e capacitação tecnológica, por intermédio da agência e através da universidade particular, contratada para o referido projeto. A inovação não se restringiu, apenas, ao desenvolvimento de produtos, mas, principalmente, se deu na gestão inovadora de processos internos, resultando na capitalização das empresas envolvidas, em decorrência da utilização da estrutura da universidade local, responsável, dentro do modelo Triple Helix, por prover a consultoria em gestão e tecnologia.

Os resultados da pesquisa, que evidenciaram notável melhoria no desempenho das empresas que participaram do programa, através de indicadores como crescimento de lucro operacional entre $27,1 \%$ a $114,6 \%$; o retorno sobre Ativo Total que cresceu entre $111,5 \%$ a 279,4\%; evolução dos índices de liquidez entre $62,6 \%$ e 173,4\%, bem como a redução do custo médio de desenvolvimento, por 
produto, de $44 \%$ a $69 \%$, e do tempo médio de desenvolvimento para 6 a 22 dias, permitem afirmar que o referido modelo pode ser uma alternativa para o crescimento e desenvolvimento das MPEs. É natural, entretanto, que o assunto mereça maior aprofundamento e os autores deixam o convite para o desenvolvimento de novos estudos sobre o tema.

\section{Referências:}

ALCHIAN, A. A.; DEMSETZ, H. Produção, custos de informação e organização econômica. Revista de Administração de Empresas - RAE, v.45, n.3, p. 70-92108, 2005.

ANDREWS, K. R. The concept of corporate strategy. Rev. ed. Homewood: Richard D. Irwin, 1980.

ASSINTECAL: Banco de dados. Disponível em <http://ASSINTECAL.org.br> Acesso em 13.dez.2006.

BERMAN, S. J.; HAGAN, J. How technology-driven business strategy can spur innovation and growth. Strategy \& Leadership; 2006; 34, 2.

BOATH, D.; HESS, P.; MUNCH, C. Virtual R\&D: A core competency approach to outsourcing. Pharmaceutical Executive. Jun 1996. Vol. 16, Num. 6, pg. 72, 4 pgs.

BOGLIACINO, F.; CARDONA, S. The determinants of R\&D Investment: the role of Cash flow and Capabilities. European Commission. Sevilla: IPTS Working Papers on Corporate R\&D and Innovation, Working Paper, 2012 (No. 10/2010).

BONOMA, T. V. Case research in marketing: opportunities, problems, and process. Journal of Marketing Research, v.22, n.2, p.199-208, 1985.

BORNIA, A. C. Análise gerencial de custos: aplicação em empresas modernas. 1. ed. Porto Alegre: BOOKMAN, 2002.

BRISOLLA, S.; CORDER, S.; GOMES, E.; MELLO, D.. As relações universidadeempresa-governo: Um estudo sobre a Universidade Estadual de Campinas (Unicamp). Educação \& Sociedade, ano XVIII, no 61, Dezembro/1997. 
CASAROTTO, N. F., PIRES, L. H. Redes de pequenas e médias empresas e desenvolvimento local. São Paulo: Atlas, 1999.

CHAM, K. W. A estratégia do Oceano Azul - como criar novos mercados e tornar a concorrência irrelevante. 5ª Ed. Rio de Janeiro: Elsevier, 2005.

CHANDLER, A. D. Organizational Capabilities and the Economic History of the Industrial Enterprise. The Journal of Economic Perspectives, v. 6, n.3, 1992.

CHRISTENSEN, . F. Corporate strategy and the management of innovation and technology. Industrial and Corporate Change, v.11, n.2, pp. 263-28, 2002.

CHRISTENSEN, C. M.; RAYNOR, M. E. O Crescimento pela Inovação - Como crescer de forma sustentada e reinventar o sucesso. Rio de Janeiro, Elsevier, 2003.

COASE, R. H. The nature of the firm. Economica, v.4, 16, pp.386-405, 1937.

COGAN, Samuel. Activity-Based Costing (ABC): a poderosa estratégia empresarial. 3. ed. São Paulo, SP: Pioneira, c2000

COSTA, A. B. Estudo da competitividade de cadeias integradas no Brasil: impactos das zonas de livre comércio. Campinas: Unicamp, 2002.

CURRY, S. J.; CLAYTON, R. H. Business Innovation Strategies. Business Quarterly, v. 56, n. 3, 1992.

DAGNINO, R. A relação universidade-empresa no Brasil e o "Argumento da Hélice Tripla”. Revista Brasileira de Inovação, v 2, n.2, pp. 267-307, 2003.

DEB, C. Accessing external sources of technology. Research Technology Management, v. 2, 1996.

DEMO, Pedro. Pesquisa e Informação Qualitativa. São Paulo: Editora Papirus, 2006.

DONCKELS, R.; LAMBRECHT, J. The network position of small businesses: an explanatory model. Journal of Small Business Management, v.35, n.2; p.13-25, 1997. 
DUTRA, I. S. Redes empresariais de negócios estratégicas no contexto de governança supraempresarial: estudo e metodologia para seus atributos de poder competitivo. 2009,268 f. Tese (Doutorado em Administração). Faculdade de Economia, Adm,inistração e Contabilidade, Universidade de São Paulo, São Paulo, 2009.

FERREIRA, J. A. S. Contabilidade de custos. São Paulo: Pearson Prentice Hall, 2007.

GHEMAWAT, P. Competition and business strategy in historical perspective. Business Review, v.76, n. 1, pp. 37-74, 2002.

GIULIANE, E. The selective nature of knowledge networks in clusters: evidence from the wine industry. Journal of Economic Geography, v. 7, pp. 139-168, 2007.

GOEL, R K. On contracting for uncertain R\&D. Managerial and Decision Economics, v. 20, n. 2, 1999.

GORINI, A. P.; SIQUEIRA, H. G. Complexo coureiro-calçadista. Rio de Janeiro: BNDES, 2000.

GRANT, R. M. The Resource-Based Theory of Competitive Advantage: Implications for Strategy Formulation. California Management Review, v.33, n.3,1991.

HAMEL, G, PRAHALAD, C.K. Strategic intent. Harvard Business Review, [sv], [s.n], pp 63-74, 1989.

HARRIS, R. C.; RICHARD, C.; MORONE, J.; WERLE, M. J. The virtual R\&D laboratory. Research Technology Management, v.39, n.2, 1996.

HENARD, D. H.; MCFADYEN, M A. R\&D knowledge is power. Research Technology Management, v. 49, n.3, pp 41-47, 2006.

HERTOG, D.; THURIK, R. G. J.; ROY, A. Determinants of internal and external R\&D: Some Dutch evidence. The Economist, v.141, n. 2, 1993.

IBGE. Pesquisa Mensal de Emprego - PME. Disponível em: <http://www.ibge.gov.br/ home/estatistica/indicadores/trabalhoerendimento/pme>. Acesso em: 20 abr. 2014.

KAPLAN, R.; NORTON, D. (2004). Mapas estratégicos: convertendo ativos intangíveis em resultados tangíveis. Rio de Janeiro : Elsevier, 2004.

SCHEREIBER, D. Modelo Triple Helix como estratégia de gestão de custos em inovação em redes de MPE's. Revista de Empreendedorismo e Gestão de Pequenas Empresas, v.2, n.3, 2013. 
KAY, J. Fundamentos do sucesso empresarial: como as estratégias agregam valor. Rio de Janeiro: Campus, 1996.

KRAMER, Greg. Outsourcing R\&D. Appliance Manufacturer, v.50, n.8, 2002.

LANGLOIS, Richard N. The vanishing hand: the changing dynamics of industrial capitalism. Industrial and Corporate Change, v.12, n.2, p.351-885, 2003.

LASTRES, H. M. M.; CASSIOLATO, J. E. Arranjos e sistemas produtivos locais na indústria brasileira. 2001. Disponível em: <http://www.desenvolvimento.gov.br/arquivo/ sti/publicacoes/futAmaDilOportu>. Acesso em: 08 abr. 2007.

LEONE, George S. G. Custos: planejamento, implantação e controle. 3. ed São Paulo: Atlas, 2000

LEYDESDORFF, L., ETZKOWITZ, H. Emergence of a Triple Helix of UniversityIndustry-Government Relations. Science and Public Policy v.23, n.5, p.279-86, 1996.

LOASBY, Brian J. The organisation of capabilities. Journal of Economic Behavior \& Organization, v. 35, 1998.

MAHONEY, J. T.; PANDIAN, P. J. The resource-based view within the conversation of strategic management. Strategic Management Journal, v. 13, n. 5, June, 1992.

MARTINS, E. Contabilidade de custos. 9. ed. São Paulo: ATLAS, 2006.

MEGLIORINI, E. Custos: análise e gestão. 2. ed São Paulo: Pearson Prentice-Hall, 2006

MILLER, W. L.; MORRIS, L. 4th Generation R\&D: Managing Knowledge, Technology, and Innovation. Nova lorque, John Wiley \& Sons, Inc., 1998.

MINERVINI, N. O exportador. Makron Books, São Paulo, 2001.

MINTZBERG, H. Strategy-making in three modes. California Management Review, v. 26, n. 2, pp. 44-53, 1973. 
MINTZBERG, H. Patterns in strategy formation. Management Science, v.24, n.9, 1978.

MORRISON, S. Outsourcing growth keeps prognosis upbeat. Chemical Week, v.164, n.8, 2002.

MORT, Joe. Nature, value and pursuit of reliable corporate knowledge. Journal of Knowledge Management; v.5, n.3, pp.222-230, 2001.

MULS, Leonardo M. Desenvolvimento local, espaço e território: o conceito de capital social e a importância da formação de redes entre organismos e instituições locais. Economia, Brasília (DF), v. 9, n. 1, pp.1-21, 2008.

NAKAGAWA, Masayuki. Gestão Estratégica de Custos. São Paulo: ATLAS, 1993.

PENROSE, Edith. The theory of the growth of the firm. New York: Wiley, 1959.

PORTER, Michael E. Vantagem Competitiva - Criando e Sustentando um Desempenho Superior. Rio de Janeiro: Campus, 1989.

REINL, L.; KELLIHER, F. Cooperative micro-firm strategies: leveraging resources through learning networks. International Journal of Entrepreneurship and Innovation, v. 11, n. 2, pp. 141-158, 2010.

SABATO, J. A.; BOTANA, N. La ciencia y la tecnología en el desarrollo futuro de América Latina in: SABATO, J. A. El pensamiento latinoamericano en la problemática ciencia-tecnología-desarrollo-dependencia, Buenos Aires: Paidos, 1975. pp. 132-143.

SCHUMPETER, J. A. Teoria do desenvolvimento econômico: uma investigação sobre lucros, capital, crédito, juro e o ciclo econômico. São Paulo: Abril Cultural, 1982.

SILVESTRE, W. C. Sistema de custos ABC: uma visão avançada para tecnologia de informação e avaliação de desempenho. São Paulo: Atlas, 2002

SWEDBERG, R. Economic versus sociological approaches to organization theory. In: TSOUKAS, Haridimo; KNUDSEN, Christian (Eds). The Oxford handbook of organization theory. Oxford: Oxford University Press, 2003. p.373391. 
TERRA, B.; ETZKOWITZ, H. A Universidade Empreendedora e a Sociedade da Nova Era. Disponível em: www.competenet.org.br/evento/branca.pdf. Acessado em 15/04/2007.

TIDD, J.; BESSANT, J.; PAVITT, K. Managing innovation: integrating technological, market and organizational change. 3. ed. Chichester: John Wiley \& Sons, Ltd, 2005.

TULL, D. S.; HAWKINS, D. I. Marketing Research, Meaning, Measurement and Method. Macmillan Publishing Co., Inc., London, 1976

VANDERBECK, E. J.; NAGY, C. F. Contabilidade de custos. 11. ed. São Paulo: Thomson Learning, 2003

WERNERFELT, B. A resource-based view of the firm. Strategic Management Journal, v.5, n.2, p. 171-180, 1984.

WESTWOOD, A. R. C.; SEKINE, Y. Fostering Creativity and Innovation in an Industrial R\&D Laboratory. Research Technology Management, v.31, n.4, 1988.

WHITTINGTON, R. O que é estratégia? São Paulo: Pioneira Thomson Learning, 2002.

WILLIAMSON, O. E. Economics and organization: a primer. Califórnia Management Review, v.38, n.2, p.131-146, 1996.

YIN, R. Estudo de caso: planejamento e métodos. Porto Alegre: Bookman, 2005.

ZACCARELLI, S. B.; et al. Clusters e Redes de Negócios: uma nova visão para a gestão dos negócios. São Paulo: Atlas, 2008.

Artigo recebido em: 23/12/2013. Aprovado em 14/01/2014 